\title{
Community capital and the role of the state: an empowering approach to personalisation
}

Tricia Jones*

University of Birmingham

\begin{abstract}
Personalisation was a key element in reform to the Adult Social Care system in England, exploring long-term funding options in response to demographic change where people are increasingly living longer with complex conditions and needs (Department of Health, 2007). Self-directed support is central to this reform to enable recipients of social care to choose and commission their own services. Reform was not expected to require structural reorganisation but local authority leadership was anticipated to promote genuine partnerships between social care providers, users and their carers as well as the wider community. However, there is potential for a shift in power to service users which goes beyond collaboration, especially where there is scope to build long-term relationships around long-term needs.

This study is based on one local authority partner's innovative development of local communities' social capital around personal budgets for vulnerable adults, which set out to grasp the potential that personalisation offered in enabling different ways of service delivery that were nearer to what service users and their carers wanted. Although now being addressed, there has been less research into the impact of personalisation on the crucial role of carers than on any other group, which is fundamental to the personalisation agenda reaching its real objectives. The study considers the role played by the local authority in this agenda in the light of claims that reforms are increasingly shrinking the role of the state. Taking an asset-based approach to informal care via social networks, this local authority partner was able to empower a community-run organisation in one of its most deprived and diverse wards by brokering support for vulnerable residents and embracing a neighbourhood perspective to examine collective as well as individual solutions. Conclusions reflect on the importance of the role of the state in achieving community capital.
\end{abstract}

Keywords: social/community capital; the state; asset-based approach; personalisation.

\section{Introduction}

This paper is the product of case study research into a neighbourhood innovation that sought to address service provision in Adult Social Care within the policy context of 
personalisation and community empowerment. Carers are vital to the successful implementation of personalisation because the delivery of adult social care could not be sustained without the 6.4 million people who voluntarily fulfil this role (Larkin and Dickinson, 2011). The personalisation agenda in England evolved with a strong sense of inter-sector collaboration although it has been more recently contextualised within the volunteering of Big Society rhetoric.

An urgent need for a new adult care system was demonstrated in research conducted by the Labour Government from 2000 onwards with a total of 150 Councils with Social Services responsibilities for referrals, assessments and support packages (Department of Health (DoH), 2005). Since 2005 national legislative directives have taken this forward (HM Government, 2008; DoH, 2008; ODI, 2008). National and local leadership working with the local NHS, third and private sector providers, users and carers as well as the local community was considered essential to achieve system-wide transformation (DoH, 2007). Personal budgets for service users and their carers have been mandatory within care plans since 2012 (Miller and Larkin, 2013) so those assessed by local authorities as eligible for Adult Social Care support are at the centre of this reform.

One of the main challenges when assessing the positive and negative impacts of self-directed support is the complexity of local authority systems. While there is evidence that the needs of carers are neglected there is an emerging knowledge base regarding personalisation and carers that indicates there is potential for more choice and control (Miller and Larkin, 2013). According to a European-wide study, carers can experience many adverse consequences, including disrupted employment, lost income, poor health and stress, (Mansell et al., 2007) yet family carers and frequently friends and local neighbours play a largely unacknowledged role in helping vulnerable adults find their way through the bureaucratic and complex system of social care provision (Larkin and Dickinson, 2011; Edwards, 2012). The potential for change lies in collaborative redefinition of care needs; in revised forms of delivery and in developing and sustaining long-term timescales to meet long-term needs (Bovaird, 2007; Needham and Carr, 2009; Dickinson and Glasby, 2010). Miller and Larkin's recent research (2013: 6) suggests a need for a whole systems approach, integrating all dimensions and aspects of service provision and delivery, reflecting new organisational culture to meet the challenge.

The case study is based on a project in the West Midlands led by Sandwell Metropolitan Borough Council (MBC) in the Soho/Victoria ward of Smethwick: Sandwell set out to bring the personalisation and empowerment agendas together using the 'Friends and Neighbours' initiative to increase social capital by taking an asset-based approach, which simply means "instead of viewing residents as 'problems', where action is seen as compensating for a deficit, communities and residents are seen as being rich in talents and abilities" (Edwards, 2012: 2).

Research methodology was based on a process-focused strategy of evidence gathering from the case study to capture the power dynamics evident in causal relations that can relocate power from service provider to user. It concludes that the role of the local authority as a necessary broker is indispensable in this process contesting the proposition of 'Big Society, small State'.

\section{The personalisation agenda}

Personalisation is an international phenomenon with a significant history and intent that is broader than mere political intervention (Larkin and Dickinson, 2011). More recently it is "the means through which a number of debates over the relationship 
between citizen and state have been conducted" (ibid 2013: 5). It underpinned reform to Adult Social Care in England based on the 2007 Comprehensive Spending Review in response to demographic challenges; increased longevity complicated by conditions such as dementia and chronic illnesses; changing family structures and people's aspirations to receive care in their own home for as long as possible. Founded on collaboration between central and local Government, professionals and service users, the reform set out to be the first public review reform programme to be "co-produced, co-developed and co-evaluated" (DoH, 2007:1). It intended to bring community-based health provision together with wider issues of benefits advice, education, training, employment and housing. Reports set out to revise the role of social workers engaged in assessments within personalisation to achieve social change, well-being, human rights and social justice (Lymbery, 2012).

In 2011 the Commission for Funding of Care and Support headed by Andrew Dilnot made a series of recommendations to the Coalition Government based on the same conclusion that the existing provision needed urgent reform. One of the major problems identified in the report was that people were unable to protect themselves against very high costs, making their long-term future for care uncertain. The report recommended reforms to achieve national eligibility, portable entitlements and emphasised the importance of information, advice and advocacy (Dilnot, 2011). This reform was generally supported although seen by some as not going far enough as there is little mention of service users and user-led organisations when it is well-known that a voice for carers and users is central to ensuring that change is "truly rooted and costeffective" (Beresford, 2011: 1).

The difference in emphasis between the previous and current Government policy on personalisation regarding the role of the state is apparent (Lymbery, 2012: 786). The Labour Government stressed, "the state should empower citizens to shape their own lives and the services they receive" (DoH, 2008: 4). The Coalition Government emphasised the purpose of the policy as allowing "people to have the freedom to choose the services that are right for them" (DoH, 2010: 4). Big Society is a concept that is open to "as many interpretations as there are ideological positions" (Albrow, 2012: 107) yet the counterparts to Big Society being 'small state' leaves little room for partnership working between local authority and constituent communities. The 'Friends and Neighbours' asset-based approach allows us to explore the role of the state in the empowerment process at local level.

\section{Asset-based approach to community capital}

Sustainable community involvement has been part of a growing movement for two decades. Primary building blocks include local assets in the form of residents' skills and abilities and the supportive functions of local institutions (McKnight and Kretzmann, 1993; Mathie and Cunningham, 2003; Hufford et al., 2009; Russell, 2011). This is in sharp contrast to the alternative problems-orientated needs-mapping approach to deprived and troubled neighbourhoods that has had a devastating effect in some inner city areas. As a result of the latter approach it can be argued that some neighbourhoods have now become:

environments of service where behaviours are affected because residents come to believe that their well-being depends upon being a client with special needs that can only be met by outsiders (McKnight and Kretzmann, 1993: 2).

However, an asset-based approach to such neighbourhoods in terms of social care is likely to find that contrary to the problematisation of needs-mapping, many people are already providing informal care for each other and there is potential to "increase 
the 'social capital' which results from informal exchanges and interactions between residents" (Edwards, 2012: 2).

Approaches to community involvement can best be located within the theory of social capital (Putnam, 2000; Lowndes, 2000; Harper, 2001; Farr, 2004; Szreter and Woolcock, 2004; Fine, 2007). Putnam (2000) categorised two forms of social capital; 'bonding' capital, that is, the trust and co-operation that exists between members of a network group with the same or similar identities; and 'bridging' capital that relates to mutual respect and collaboration that develops between people who are not from the same social identity grouping. Szreter and Woolcock (2004) argued the necessity of a third category of social capital, adding a community dimension to social capital theory - that of 'linking' capital to address the inequality of power between collaborative partners:

(J)ust as health outcomes can be improved by expanding the quality and quantity of bonding social capital (among friends, family and neighbours) and bridging social capital (trusting relations between those from different demographic and spatial groups), so, too, is it crucial to facilitate the building of linking social capital across power differentials (Szreter and Woolcock, 2004: 655).

In relation to public service provision, Big Society thinking about the centrality of civic participation is at the forefront of this debate where harnessing social capital is considered key to the Government's localism agenda of locating communities centre stage (Cabinet Office, 2010).

Although Putnam conceptualises social capital as contributing towards the quality of relationships between citizens in an effectively governed society, Szreter (2002, 2012) argues there is a missing discourse about the role of the state in this analysis. Furthermore, within Big Society thinking, the voluntary sector working through local communities is promoted as the agency of social recovery, "from state power to people power" (Cameron, 2010). Szreter (2012: 39) asks the fundamental question: "what is the role of local government in all this?"

This conceptualisation of 'social capital' helps to portray a shift in power to service users via collaboration that acts as a conduit for challenging ideology, access and control over resources and in transforming institutional relations (Batliwala, 2007). It is also an effective term when considering approaches to capacity building associated with community empowerment in collaborative working. What needs to be recognised is that an asset-based approach demands that capacity building works both ways. Within the theoretical framework of bonding, bridging and linking capital there is a gap in applied research identifying the often overlooked element of agency within the dynamics.

As detailed in the context below the 'Friends and Neighbours' case study is uniquely positioned, and at a critical stage of development, to enable productive examination of the process of relocation of power from service providers to the community and to identify the role of the local authority as an agent of change.

\section{Case study context}

During 2009 the Department of Health commissioned the Stamford Forum, an international, change-orientated partnership organisation, to look at alternative solutions to the challenge of combining personalisation with community empowerment. The Stamford Forum was conceived in early 2009 to consider some of the key issues and unspoken deficits in modern politics and led the Developing and Empowering 
Resources in Communities Initiative (DERIC) to pilot an asset-based model to personalisation in Leeds, Belfast and Sandwell.

The magic of this possibility is clear: vulnerable people would become community assets instead of a problem... This, surely, lies at the heart of the community empowerment and individualisation agendas - local people incentivised to help their vulnerable neighbours and value each others' presence (Brazil, 2009).

Sandwell is located in the Black Country which was at the heart of the industrial revolution where people lived in close knit neighbourhoods often connected to mines, iron foundries, steelworks, local coking operations and factories. Although the heavy industry has gone, there is still a proud tradition of manufacturing. The Borough has seen a small population growth reversing the long-term decline since the 1960s. Sandwell's communities are now much more diverse, but local networks through work, faith, schools and neighbourhoods are valued. "Community cohesion is good. Sandwell seems to have the scope to challenge the assertion that 'social capital' is on the decline" (Edwards, 2012: 2).

The DERIC pilot is taking place in the Soho/Victoria Ward where statistics ${ }^{1}$ show it houses the highest proportion of BAME population for the Borough and the highest proportion of people of working age registered as seeking employment. When long-term illness and poor general health statistics are taken together it scores the highest percentage for the Borough. Interestingly it also displays a higher than average percentage of people qualified to degree level and above and at the same time has a higher than Borough average percentage of people with no qualifications at all.

Sandwell's challenge is targeting individual neighbourhoods and understanding local priorities. The Council is aware that "the more people feel their priorities drive local improvement, the better perceptions are of local public service providers" (Wright, 2010: 8). The refreshed Anti-Poverty Strategy 2010-2013 identified personalisation as a significant issue and proposed key actions that increased social capital through new, mutually beneficial schemes. This conceptual approach aims to improve the quality of life for older and disabled residents as well as cultivate community-based volunteering and employment opportunities (Edwards, 2010).

\section{'Friends and Neighbours'}

'Friends and Neighbours' developed within a neighbourhood where approximately half the housing is provided by social landlords and the rest via private, mostly rented sector provision. Due to low turnover and high demand there is very little movement within the social-rented sector. The area is particularly diverse: Local authority housing management officers estimate there are 12,000 residents from 71 different countries living in 3,400 properties. The mix includes Black and White British, established BAME; economic migrants; and refugees and asylum seekers.

The 'Friends and Neighbours' Community Interest Company $(\mathrm{CIC})$ is underpinned by an innovative financial model. Direct cash payments for those eligible for Fair Access to Care Services (FACS) are central to the personalisation agenda in bringing more control over service users' support packages. Once assessment has been made, Personal Budgets are allocated and have been rolled out since 2008. Users can either take their Personal Budget as a direct payment, leave the Council with the responsibility to commission the services or have some combination of the two. Personal Budgets have been critiqued by bodies such as the New Economics Foundation: "Personal budgets were never intended... to replace relationships with 
market transactions. But when they are used by policy-makers instead of rebuilding social networks, this can be the outcome" (Stephens et al., 2008: 16).

Case study assessments are done very differently in three ways; they are completed with everyone needing care not just those eligible for Personal Budgets; they are not individualistic but include all family and friends (often neighbours) involved with the users and they are designed as 'living plans' rather than 'support packages' to reflect the long-term holistic approach.

Value is added and costed through volunteers working at different levels; good neighbours, community support and training and development to develop a pool of 'Community Supporters'. Much is done in partnership, for example with the local Hospital that plans to set up a training hub in the disused Neighbourhood Office to enable skill sharing and career progression. The 'Friends and Neighbours' CIC is developing a business plan and will have autonomy in consultation with all members of the community over what to do with surplus revenue.

\section{Methodology}

A process-focused research approach has been adopted to examine the particular and add depth, richer description and fuller understanding to an already established theoretical or empirically founded proposition (Bergen and While, 2000; Stake, 2003). The strength of this approach into the 'Friends and Neighbours' initiative has been early development of a conceptual structure of this case study, revolved around the simple proposition that collaboration in the policy context of the personalisation agenda enables a shift in power from service providers to service users.

In this way it becomes possible to generalise at the level of theory as long as a theoretical framework is developed between data from different sources to enable causal relationships to be examined (Yin, 1984; 1989; 1994). Perakyla (2004: 297) suggests an alternative to looking for generalisability when identifying the outcome of case study research is in being able to test the notion of different "possible social practices". She argues that this works "even if the practices are not actualised in similar ways across different settings". For Sandwell, therefore, rolling out the "Friends and Neighbours' is an approach and not a blueprint. It does not mean 'one size fits all'; so communities in other localities can influence local responses and possible social practice differently.

Participants were personally invited to take part in the study and free to withdraw their contribution at any time. Methods involved active listening techniques to enable a co-creational approach to data gathering during a series of unstructured interviews and focus groups conducted with staff; resident Board members; local voluntary organisations and other stakeholders. Observations were conducted by invitation during Board and Steering Group meetings.

A grounded theory approach to content analysis of transcripts, documentation from previous meeting and records of events was undertaken to identify whether there was a perceived shift in ideology, resource distribution and institutional relations to build on the theory of asset-based approaches to community empowerment. The size of the case study means individual contributions can easily be identified and some have been particularly frank following reassurances (at the start of the interview) that they will not be personally attributed. Therefore, quotations have been anonymised to protect confidentiality.

If the branding of 'Friends and Neighbours' is to be rolled out by Sandwell Council as anticipated to other areas of the Borough, there may be further research 
opportunities to examine replication and discover whether the initial theory needs further revision and retesting elsewhere.

\section{Findings}

In an attempt to capture the dynamics at play, themes based on an understanding of community empowerment emerged through a grounded analysis of the causal relationships between respondents and were endorsed in terms of their significance to the study with key participants. Themes comprised the policy and polity context where local contingencies and policy innovation collide; trust, that was much in evidence from data gathered from different perspectives; capacity building evolved from within the theoretical framework of asset-based approaches to community capital; and reference to some of the tension management, which related closely to the final theme of relocation of power, evidencing the existence of dynamic change within the case study arena.

\section{Policy and polity context}

The link between policy and polity is an interesting one within this case study and the dynamic impact on the case study was evident on interlinking levels and colliding timescales. At the same time that the Department of Health was engaging the Stamford Forum to study the connection between community engagement and personalisation under the banner of capacity building, there was activity at local authority level around officer recruitment and new council leadership that influenced the choice of Sandwell as a pilot site.

The recently appointed Anti-Poverty Manager prompted a broad anti-poverty strategy consultation to refresh the approach. This was a tangible exercise to establish issues and practical needs with vulnerable residents. What emerged from wide-ranging discussions with those in receipt of Adult Social Care within the local community was a "frustration with systems and bureaucracy hence people turned to friends and neighbours for support" (Local Authority officer). This key finding evidenced the first indication of an empowered collective voice identified by Dickinson and Glasby (2010) and by Beresford (2011) as a gap in the Dilnot reform. The approach was brand-named using the words of local people to establish the 'Friends and Neighbours' initiative.

The initiative grew organically from previous Council-led community development and neighbourhood management work where a steering group of residents from diverse backgrounds and communities had been galvanized to look at aspects of neighbourhood planning in the area. The 'Friends and Neighbours' CIC was codeveloped with residents from a previous Council-led project through the Working Neighbourhoods Fund.

A further positive contribution to the polity context linked to this policy was the election of a new political leadership. From a network perspective, the new Council leader and local Ward Councillor was previously the Cabinet Member for Social Care and is a community health professional who understands what the challenges entailed. He provided, "someone in that strategic position who understands what it is we are trying to do" (Resident Board Member). Another local Councillor acted as a resident Director to give the initiative "political legitimacy" (Resident Board Member). 
Trust

Trust is essential to relational empowerment and nurturing trust is an important activity in developing community capital. Three years of outreach work had built up trust with local residents, making this neighbourhood an ideal choice for the DERIC pilot. Importantly, links had been built within the neighbourhood planning learning process at the same time that the national personalisation agenda was emerging. Residents had been involved in recruitment and selection of masterplanners and an independent tenants' advisor. Trust-building had been done systematically with all stakeholders involved:

The challenges are around changing mindsets. Two or three people were very cynical and it goes up the project. You have to start with the community. At an initial meeting about what 'Friends and Neighbours' could be and how it could be shaped some reacted saying 'We've heard it all before", so confidence building and assurances were developed by working things through with people. We needed to show that what's been discussed at this meeting will be taken on board and affects the next meeting and the next meetings (Community Participation Officer).

Local Council officers were acutely aware that mutual trust was at the core of meaningful engagement. Subsequently there was an understanding of the basis for lack of trust in officialdom when home visits are made to assess initial needs:

Trust comes into it and that's why I don't rush assessment. When we first visit they think we're coming to take something away they're not used to being given something. The first thing they say is 'I've got no money left' (Assessment Officer).

Conversely, there was also evidence of the need for officialdom to trust the community to define needs realistically:

Sometimes they (the bureaucracy) imagine that if people are allowed to ask for anything they will ask for large and unimaginable things but what we find is people ask for low level things, for example, someone to pop in just for half an hour to have a chat (Resident Board Member).

Trust in staff was evident in the way they were selected for their maturity and experience and given an unhampered remit. Certainly "expert staff on the ground" was considered essential by one local voluntary sector organisation that also engaged in outreach. This was a realization that grew with the approach:

Previously the Project had a student placement but wanted somebody 'more formed in social care already and more mature', someone who would have a better grounding (Voluntary Organisation Member).

The most significant indication of trust in staff was evident in the lack of corporate, prescriptive and directive instructions for a priori outcomes, targets, milestones and project planning as this participant endorsed:

It was quite interesting having had many years experience in similar jobs but it was the first time that I had been given a blank piece of paper... to work with the community to create an agenda and because we didn't have pressure of having to deliver someone else's outcomes under the microscope we were able to go out into the community and start to build there (Community Participation Officer). 


\section{Capacity building}

There appeared to be a close link between the "blank-sheet" approach taken to trusting experienced and seasoned staff members to do the work and the way they were then permitted to operate. One local authority officer described the approach as:

the kind of community development we would have adopted twenty years ago about identifying local needs and working with local people to come up with solutions.

It was evident that sustained capacity-building had a positive effect on crosscommunity collaboration: "One of the keys of 'Friends and Neighbours' is that it's not attached to any one section of the community or any one community or tenure" (Resident Board Member).

Subsequently the Board is made up of diverse members with a range of talents and professions. One Board meeting demonstrated mutual learning between members where the Chairperson encouraged discussion. Despite differences of opinion, mutual respect was obvious between seasoned activists from the Tenants' and Residents' movement; newcomers from voluntary refugee support organisations; senior professional managers; and local BAME leaders. One Board Member captured their collective aim as creating "proof that we can succeed as professionals where professionals are failing".

Where the Board provides leadership, all residents in the area are eligible to take part in decision-making procedures. Abilities in the area are extremely wide-ranging:

While some have been workless for two, three and even sometimes four generations and might need pre-basis skill training, some of the newcomers have high skill levels that we are only just discovering. For example, a number of Albanian women who come from farming communities have lace making skills. We have a radiographer who has relocated from London; a number of doctors; and some residents have languages 'coming out of their ears!' (Resident Board Member).

The approach demanded open-mindedness and a clear mandate that the CIC would be the vehicle to pull all these strands together. One perception of the future development of the initiative entailed fundamental change in Adult Social Care package provision where a "disjointed" service has been delivered in "isolation in a siloed system" (Assessment Officer). The approach allows for matching clients with Community Supporters based on local knowledge of people's needs and personalities:

for example we have a couple where the man is frail but very lively and his wife suffers from dementia. They have been matched with a feisty young woman who is ideal for the situation because she can join in with banter as well as deal with different needs within the family (Assessment Officer).

Neither are those in receipt of care excluded from contributing to the system of community support: "we have a carpenter with health problems but he is contributing support to a local youth centre" (Resident Board Member).

\section{Tension management}

Power redistribution is often fraught with tension and conflict yet disagreement at Board and Steering Group meetings was considered healthy and normative so "that conflict and debate is very upfront where resolve can be pursued" (Resident Board Member). Records indicated that debate ranged from membership eligibility; election of 
Directors; confidentiality issues and the necessary skill-sets of volunteers. The creation of a forum either at steering group meetings or CIC Board meetings appeared, from previous minutes, to facilitate conflict resolution and provide the means for creating mechanisms to counter tension in the future. For example at one CIC Board meeting there was much discussion about individual members having been "put on the spot" by outside bodies asking them for comment and contribution in wider forums. Following a robust discussion the Board decided to formulate a Communications Protocol that meant all invitations to promote or disseminate their work would go through the Chair to allow for constitutional consideration at the next Board meeting.

One indication of inter-sector tension between the local authority and the Community Interest Company appeared to be part of the process of relocation of power. It entailed the role of the Council in relation to the $\mathrm{CIC}$ and surfaced at a Board meeting where independence and autonomy were being widely debated. It was clear there were different perceptions about the nature of partnership relations with the Council. Later discussions with individual participants demonstrated that the nuanced difference between ownership and control was going to be an on-going debate where the CIC may come to realise the advantages of recognition and legitimacy that a continued partnership with the Council would bring:

People round that group are astute and there is a level of understanding of wider politics that's growing. We wouldn't be where we are without the support of the leader of the Council - it would be very naive not to acknowledge that contribution (Resident Board Member).

It is difficult to assess how significant tensions are within this case study as it is in an early stage of development and conflict and resolution are integral to its evolution. There was a perception that the CIC had "ruffled feathers" (Voluntary Organisation Member) of some of the local voluntary organisations but another participant attributed the tension to "misinformation and the misconception that the $\mathrm{CIC}$ will become the preferred care provider of the Council" (Voluntary Organisation Member). The longerterm thinking involved a process of "changing mindsets" and an understanding that there was a political dimension to the response to economic change exacting the kind of organisational cultural change cited by Larkin and Dickinson (2011). A future tension was anticipated surrounding the impact of working within timescales where the approach was built on allowing sufficient time for engagement, capacity and cohesion to "evolve" (Community Participation Officer) before rolling the model out Borough-wide.

\section{Relocation of power}

One of the recurrent themes throughout the case study was the redefinition of established concepts to change the culture of Adult Social Care. Clinical definitions, for instance, of 'vulnerability' were opened to reinterpretation:

People needed to determine what 'vulnerability' meant and we found that it was not just the elderly and frail but also those from newer communities/single parents and people with for instance drink and drugs problems that were considered vulnerable by local residents. It was clear that the concept was quite different to the Adult Social Care model of vulnerability (Assessment Officer).

There was a strategic effort to redefine the notion of volunteering (Woods, 2010), to reflect the stepped opportunities that residents may want to take advantage of within a series of options:

To get involved as a good neighbour; to get involved and develop onto the Carers' Programme; to get involved and pursue training and development career-wise". 
By calling them 'Community Supporters' we wanted to change the old ideology of what a volunteer was (Resident Board Member).

Central to the approach was the attempt to tackle the personalisation agenda at assessment stage. The present system was criticised as being narrow, disjointed and wasteful of resources. For example:

A man might receive FACS but his wife's needs as a carer are overlooked (Resident Board Member).

...both people within a couple receiving FACS with agencies visiting at different times without any coherence. It looks at individuals in isolation only and can only deal with the care aspect of people's lives (Assessment Officer).

The review of concepts, attitudes and service parameters served to develop a different way of working that achieved wider recognition and increased influence for people around the recipient of personal budgets. For example:

One family, there was three members I worked with and another there were five members in there but each one of those people l'd find out something about them to see how they linked in together. If they were removed from that equation what then would the support package look like? We try to look at everybody's input for example what impact would it have if that person had to go and have knee surgery? (Assessment Officer).

\section{Conclusions}

Undoubtedly the carers' role is fundamental to the realisation of the personalisation agenda but this case study suggests this huge body of community capital cannot personify the rhetoric of Big Society on its own. Sandwell did not set out to ratify the role of the state in releasing capital, rather its aim was to "challenge the assertion that social capital is on the decline" (Edwards, 2012: 2) exemplified in the asset-based approach taken to development of the community capital of the multiple and diverse communities living within the area. Findings suggest that this ethos drove the process at national, local and neighbourhood level. In bringing together national consultancy, local political leadership and voluntary and resident organisations a forum was created where brokerage, negotiation around power differentials and change could take place and multiply as envisaged by the Stamford Forum, in replicable form (Brazil, 2009). This process occurred within the context of the Department of Health's (2007: 1) broadly shared vision of a transformation of Adult Social Care that depended on winning the "hearts and minds of all stakeholders".

The value placed on "suitably skilled staff" (Mansell, et al., 2007: 9) assisted in a return to the kind of community development practices in place "twenty years ago". This was evident in practical ways such as care assessments which asked "residents to think more widely about what would help improve their quality of life; looking at options which include collective as well as individual solutions" (Edwards, 2012: 3). Findings in this case study regarding the relationship between personal budget holders, other vulnerable residents, formal and informal carers, family members, neighbours and visiting social workers reflected Lymbery's (2012) and others' vision of social work with the capacity to co-design 'living plans' in the pursuit of sustainable well-being and social change. The demand for longer timescales to build not only mutual trust but also long-term relationships to meet long-term needs (Bovaird, 2007, Stephens, et al., 2008) was implicit in this approach. 
Literature suggests that relocation of power can be evidenced by a change in ideology, resource distribution and institutional organisation. Evidence showed that redefining and rebuilding of concepts through the collective communities' voice created a serious attempt to challenge the "market logic that applies to narrow deliverables" (Stephens, et al., 2008: 8). It is apparent that this case study directly addresses concerns that some commentators have found troubling regarding: "The extent to which the policy has become inseparable from neo-liberal notions of consumerism and individualisation and directly challenges the transformational rhetoric with which it was introduced" (Lymbery, 2012: 790).

By identifying tensions, findings evidenced where power dynamics are likely to be relocated between residents, elected members and the voluntary, community and local authority sectors. One Resident Board Member was particularly insightful about future representation and accountability:

There will come a time if we're successful when there could be a perceived threat to the political status. It is inevitable with progressive community development where you achieve a shift in power. The question then is who are the elected representatives? The Board will progressively be elected by local people and the evolving differences between that and political representation will prove an interesting time.

Findings illustrated the asset-based approach to front-line staff as well as residents; and the dynamic leadership and synergy at national, Borough, ward and neighbourhood level. Community development work proved transformational as staff were liberated to work with the 'bonding' capital to be found within communities of identity and interest in the area to 'evolve' bridging capital between communities taking an asset-based approach to their diverse abilities and talents as well as putting a high value on the "core economy" instead of a "bifurcated world where all social problems are relegated either to paid professionals or to volunteers whose role is typically restricted to functioning as free labour within the silos of the non-profit world" (Stephens, et al., 2008: 3).

Finally, this study addresses Szreter's question about the role of the state within the volunteering of Big Society rhetoric. The local authority is material in creating the necessary linking capital for the 'Friends and Neighbours' $\mathrm{CIC}$ to operate. It devises a legal framework; lends political legitimacy; recognises latent value and demonstrates brokerage between social, voluntary and professional networks so that they can take on:

A democratic and empowering character where those involved are endeavouring to achieve a mutually agreed beneficial goal (or set of goals) on a basis of mutual respect, trust, and equality of status, despite the manifest inequalities in their respective positions (Szreter, 2002: 379).

\section{Notes}

1 Source: NOMIS, Census 2001 and Mid-year estimates. Cited from: http://sandwelltrends.info/custom/themedpages/memberportal/FactsMain/atlas.html ?select=Abbey

* Correspondence address: Dr Tricia Jones, Third Sector Research Centre, University of Birmingham. Email: p.a.jones.1@bham.ac.uk. Tel: 01215757711 / 07411456535. 


\section{References}

Albrow, M. (2012) Big Society as a rhetorical intervention. In: The Big Society Debate: A New Agenda for Social Welfare (eds.) Ishkanian, A. and Szreter, S. Cheltenham, UK; Northampton, MA, USA: Edward Elgar.

Batliwala, S. (2007) Taking the power out of empowerment - an experiential account. Development in Practice, 17, 4-5, 557-567.

Beresford, P. (2011) Does the Dilnot Report go far enough? Available at:

http://www.guardian.co.uk/society/joepublic/2011/jul/04/dilnot-reportrecommendations-analysis?intcmp $=239$ (accessed 07.08.2012)

Bergen, A. and While, A. (2000) A case for case studies: exploring the use of case study design in community nursing research. Journal of Advanced Nursing, 13, 4, 926934.

Bovaird, T. (2007) Beyond engagement and participation: user and community coproduction of public services. Public Administration Review, 67, 846-860.

Brazil, R. (2009) Is it time for a budgeting rethink? Individual budgets could benefit us all. Available

http://www.guardian.co.uk/society/joepublic/2009/jan/21/personal-budgetscare-health (accessed 05.08.2012)

Cabinet Office, (2010) Building Big Society. Available: http://www.cabinetoffice.gov.uk/sites/default/files/resources/building-bigsociety 0.pdf (accessed 06.08.2012)

Cameron, D. (2010) Together in the National Interest. Available at: http://www.conservatives.com/News/Speeches/2010/10/David_Cameron_Toge ther in the National Interest.aspx (accessed 05.08.2012)

Department of Health (2005) Community Care Statistics 2003-2004: Referrals, Assessments and Packages of Care, for adults: Report of findings from the 200304 RAP collection - information for England for the period 1 April 2003 to 31 March 2004. London: Department of Health.

Department of Health (2007) Putting people first: a shared vision and commitment to the transformation of adult social care services. London: Department of Health.

Department of Health (2008) Transforming Social Care, LAC (DH). London: Department of Health.

Department of Health (2010) A Vision for Adult Social Care: Capable Communities and Active Citizens. London: Department of Health.

Dickinson, H. and Glasby, J. (2010) The personalisation agenda: implications for the third sector. Birmingham: Third Sector Research Centre.

Dilnot, A. (2011) Fairer Care Funding: The Report of the Commission of Funding of Care and Support, Vol. 1. London: The Dilnot Commission.

Edwards, R. (2010) Sandwell Anti-Poverty Strategy 2010-2013: Health and Well Being Team, Adult and Community Services Division. Sandwell MBC.

Edwards, R. (2012) The changing face of adult social care in the UK: the example of “'Friends and Neighbours'”. SozialAktuell, 2, 28-29. Bern: Avenirsocial.

Farr, J. (Feb 2004) Social Capital: A Conceptual History. Political Theory, 32, 1, 6-33.

Fine, B. (Aug 2007) Social capital. Development in Practice, 17, 4 and 5, 566-574.

Harper, R. (2001) Social Capital: A review of the literature. Social Analysis and Reporting Division: Office for National Statistics.

HM Government (2008) The Case for Change: Why England Needs a New Care and Support System. London: Department of Health.

Hufford, L., West, D.C., Paterniti, D.A. and Pan, R.J. (2009) Community-Based Advocacy Training: Applying Asset-Based Community Development in Resident Education. Academic Medicine, 84, 6, 765-770.

Larkin, M. and Dickinson, H. (2011) Personalisation: what will be the impact for carers? Birmingham: Third Sector Research Centre. 
Lowndes, V. (2000) Women and Social Capital: a comment on Hall's 'Social Capital in Britain.' British Journal of Political Science, 30, 3, 533-537.

Lymbery, M. (2012) Social Work and Participation. British Journal of Social Work, 42, 4, 783-792.

Mansell, J., Knapp, M., Beadle-Brown, J. and Beecham, J. (2007) Deinstitutionalisation and community living - outcomes and costs: report of a European Study. Volume 1: Executive Summary. Canterbury: Tizard Centre, University of Kent.

Mathie, A. and Cunningham, G. (2003) From clients to citizens: Asset-Based Community Development as a strategy for community-driven development. Development in Practice, 13 (5) 474- 486.

McKnight, J. and Kretzmann, J. (1993) Building Communities from the Inside Out: A Path Toward Finding and Mobilizing a Community's Asset. Evanston IL: ABCD Institute.

Miller, R. and Larkin, M. (2013) Personalisation: the beginning of a new dawn or the end of the road for third sector support for carers? Third Sector Research Centre Working Paper 104

Needham, C. and Carr, S. (2009) SCIE Research briefing 20: the implementation of individual budget schemes in adult social care. London: Social Care Institute for Excellence. Available at: http://www.scie.org.uk/publications/briefings/files/ briefing20.pdf

Office for Disability Issues (ODI) (2008) Independent Living: A Cross-Government Strategy about Independent Living for Disabled People. London: Office for Disability Issues.

Perakyla, A. (2004) Reliability and Validity in Research Based on Naturally Occurring Social Interaction. Qualitative Research: Theory, Method and Practice. (Silverman, D. ed.) (2nd Ed.) London: Thousand Oaks, New Delhi: Sage.

Putnam, R. (2000) Bowling Alone: The Collapse and Revival of American Community New York: Simon \& Schuster Ltd.

Russell, C. (2011) Pulling back from the edge: An asset-based approach to aging well. Working with Older People, 15, 3, 96-105.

Research Sandwell (a) Sandwell Trends, Sandwell in Brief: Research Sandwell, available at: http://sandwelltrends.info/themedpages/FactsFigures(accessed 01.08.2012)

Research Sandwell (b) Sandwell Trends Ward Facts and Figures: Research Sandwell,available at: http://sandwelltrends.info/custom/themedpages/member portal/FactsMain/atlas.html?select=Abbey (accessed 01.08.2012)

Stake, R.E. (2003) Case Studies. In: Strategies of Qualitative Inquiry, Denzin, N. K. and Lincoln, Y. (eds.) (2nd ed.) Thousand Oaks, London: New Delhi: Sage.

Stephens, L., Ryan-Collins, J. and Boyle, D. (2008) Co-production: A Manifesto for growing the core economy. London: New Economics Foundation.

Szreter, S. (2002) The state of social capital: Bringing back in power, politics and history. Theory and Society, 31, 573-621.

Szreter, S. (2012) Britain's social welfare provision in the long run: the importance of accountable, well-financed local government, In: The Big Society Debate: A New Agenda for Social Welfare (Ishkanian, A. and Szreter, S. eds.) Cheltenham: UK; Northampton: MA, USA: Edward Elgar.

Szreter, S. and Woolcock, M. (2004) Health by association? Social capital, social theory and the political economy of public health. International Journal of Epidemiology, 33, 4, 650-667.

Woods, P. (2010) Social capital: the hopeful in pursuit of the impossible. Presented to the Managing New Realities Workshop, 2-3 March: Stamford Forum.

Wright, C. (2010) People, Perceptions and Place: The Sandwell Position. Sandwell: Research Sandwell. 
p. 167. Community capital and the role of the state: an empowering approach to personalisation

Yin, R.K. (1984, 1989, 1994) Case Study Research: Design and Methods. Applied Research Methods Series, Volume 5. Thousand Oaks, California: Sage. 